\title{
2. Modernity, Gender and Mining: Experiences from Papua New Guinea
}

\author{
Martha Macintyre
}

\section{Introduction}

While ideologies of human rights, gender equality and the elimination of discrimination underpin most large corporations' employment policies, counter ideologies of gender difference often prevail in practice. Based on research on two major mining projects in Papua New Guinea (PNG), this chapter will explore the ways in which modern western and contemporary Papua New Guinean ideals of femininity, maternal responsibility and the family converge to exclude women from equitable treatment in employment. The chapter constitutes personal reflections and a critique of mainstreaming policies as inadequate to the task of ensuring gender equity in the context of mining in the developing world.

The mining projects where I have undertaken research in PNG have been operated by large international companies whose websites and stated policies proclaim commitment to principles of human development; to social and economic sustainability when working in developing countries; equality of opportunity in the workforce; equal pay for equal work; localisation of the workforce; and provision of training and support for the pursuit of further education or qualifications for local people. In each place, departments devoted to implementing social responsibility match this public commitment. Human resources sections, community affairs (now almost invariably featuring 'social sustainability' in their titles or mission statements) and specially-designated positions within these departments attend to projects that are aimed at gender equity, women's activities in the community and sometimes youth affairs and recreation.

In PNG, mining is one of the major industries. It is seen by many local people as the most likely means of improving standards of living, providing employment and economic changes that people associate with development and modernity. While NGOs and international providers of government-to-government aid inevitably stress gender equality as an aim in any project within PNG, the most significant economic developments come through industrial projects (almost all resource-extractive) and within these projects, gender inequality is not salient. In fact, one could argue that it is well and truly 'mainstreamed'. Gender inequality 
is meant to be achieved by policies that are non-discriminatory rather than through policies and programs that redress the imbalances and enable women to participate equitably.

If we take the definition of gender mainstreaming from the United Nations literature (UN ECOSOC 1997; UNDP 2005) it requires a full assessment of the implications for men and women of any project so that the interests of men and women are integrated into the design and implementation of aid delivery, economic development programs and projects aimed at improving the political and social participation of people. This is meant to ensure that '... men and women benefit equally and inequality is not perpetuated. The ultimate goal is to achieve gender equality.'

Gender mainstreaming is readily comprehensible in the context of aid projects where the express aim is a managed intervention aimed at effecting changeinstitutionally, economically or socially. But when the project is a commercial enterprise, such as a mine, the transformative project is less clear. The notion of corporate social responsibility, for instance, often carries with it ideals of 'social sustainability' and non-intervention in aspects of the social and cultural lives of local people affected by economic change. The requirement of social impact analysis in some countries rests on an idea that the mine, in providing employment and developing infrastructure and services, will improve people's quality of life but should not impinge on cultural practices in ways that erode or destroy values that sustain customary sociality. Often this is interpreted as maintaining the status quo, as if 'customary ways of life' can be insulated from the upheavals generated by economic transformation.

To give examples from two mines: the influx of money from compensation, royalty payments and wages at Porgera in Enga Province enabled those men who became wealthy to pay high bride prices and marry multiple wives on an unprecedented scale. The social effects of this new practice have had destabilising effects on marriage, household composition and social harmony (Bonnell 1999; Golub 2006). Many women perceive this as having contributed to a decline in their status generally and to the erosion of customary ways of negotiating marriage. The abandonment of older wives and increasing number of wives taken from other tribal groups is seen as a factor in increased incidence of domestic violence and tensions with neighbouring groups (who view marryingin as a strategy for gaining access to benefits). Because men have greater access to financial benefits, especially employment, women sell sexual services - with the consequence of a very high incidence of sexually transmitted disease, including HIV/AIDS (Hammar 2008). These social effects were predictable and are attributable to economic and social changes brought by the influx of cash and the extension of its use in sexual relationships. However, it could be argued that measures aimed at increasing financial benefits to women, or having a 
rigid policy of gender equity in employment would have been interpreted as an assault on customary gender relations. It is also highly unlikely that people, both male and female, would support policies that require equal numbers of male and female employees.

In Lihir, when the groups of landowners set up bank accounts for the receipt of compensation and royalty payments, no women were given authority to control the accounts. An attempt by the company to insist that women landowners be named on the lists and have some control over moneys was rejected by both men and women, who viewed men's privilege in this domain as an extension of customary control over a lineage's wealth. Sensitive to accusations of cultural insensitivity, reluctant to interfere in ways that could be viewed as interfering in private financial matters within families and having no legal authority to determine how each local group deals with its money, the mining company could not respond to remedy gender inequities.

There are problems with the level of generality in notions of mainstreaming gender in mining. What does it mean to women that they benefit 'equally' from a mining project? That they have equal access to any jobs? That there are equal numbers of men and women employed? That the distribution of wages is such that men and women have equal share? The infrastructural and service benefits such as roads, hospital, schools and telecommunications can, and often, benefit women at least as much as men. Reticulated water and electricity can reduce the amount of time and effort that women expend each day transporting water and fuel. Such services can also improve health, so that respiratory illnesses associated with cooking over open fires are reduced, or a clean water supply improves hygiene and reduces waterborne diseases. Being able to wash clothes in a laundry rather than on a mosquito-infested riverbank might also mean that women are less exposed to diseases such as malaria. A gender analysis of proposed changes would identify the gender dimensions of any proposed change in order to ensure that communal benefits were spread equitably. As women's needs and aspirations in a community are often quite different from those of men, undertaking a gender analysis that identifies these distinct needs and establishing projects that ensure they are met with would seem adequate to the situation. It could also ensure that women's needs were met, an end not that is not secure by applying gender mainstreaming.

In my experience miners view such benefits ambivalently. They are a cost at a time when the profits have not begun to roll in. Mining companies recognise that electricity, water supplies, roads and hospitals are necessary for their own enterprise and as such can be extended to the local community more cheaply than other infrastructure. They are also concerned about support from local people and thus present these as being benefits that are responding to their demands. To some extent this is true - people do want roads and other services. 
But they also want housing, school buildings, money in their pockets and a chance to set up business enterprises. Here companies are less generous. They assist in establishing businesses that support their own needs - contractors who can supply goods and services to the mine. They build houses for relocatees, but not for others who simply live in the area. In short, they try to make their contributions to local communities that further their own business interests and help the mine to run smoothly. They meet the demands of their hosts as much as possible to avoid shutdowns and bad press, but these demands come mainly from men. Women rarely present themselves at meetings of stakeholders. If asked what businesses they might be interested in developing, they usually lack any experience that would suggest that they could operate a business that supplies goods or services to the mine. Their absence from negotiations at crucial initial stages means that their involvement in economic development is limited from the outset.

Given the cosmopolitan character of mining companies, they are familiar with the principles of gender equity in the workforce and it is noticeable that in PNG these are generally adhered to as standard practice. Job advertisements are gender neutral. Within the mining sector there are female graduates who work in the professions and technical areas and are paid at the same rates as men in those positions. I have encountered women who are geologists, engineers, chemists, heavy machinery operators, accountants, biologists, librarian/ archivists, environmental scientists, computer scientists and human resource managers. During the first few years of working in Lihir, when I was given access to data on applicants for positions, it was clear that with the exception of administrative positions where there was a higher percentage of female applicants, more than 90 per cent of applicants were male. Tracking over the years 1995-1997, it emerged that all women who applied with appropriate qualifications were almost certainly considered or interviewed (Macintyre 2005: 22). During the first five years of the mining project, the highest paid Papua New Guinean employees were predominantly female, with most of them in administrative positions - but there were very few of them and all were subordinate to male managers. During that time there was only one PNG man in a managerial position, all senior managers were expatriate men.

As a transnational industry, mining employs senior people (mostly men) who are able to move from project to project and often from one country to another. The fly-in/fly-out rostering policies for expatriate employees adopted in PNG favour men who are either single or married with a wife and family in their home country. The gender norms that prevail in Australia (where most expatriate managers originate or live) mean that such mining jobs are often ones that women regard as too disruptive of family life. Living on site enables people to have more normal domestic arrangements, but even then the long shifts and cyclical 
rosters do not accommodate the needs of children (see Pattenden 1998; Yrke 2005). For expatriate fly-in/fly-out workers, the bonus is in the remuneration; as Yrke found in her study, wives accepted the inconvenience and added burdens of being the sole parent most of the time because the husband earned a much higher wage than if he were in an equivalent position close to home. It is in this context that the mining industry's advertisements can appear to be nondiscriminatory - they are adapted to the gender ideologies of the industrialised nations in which men are considered primary breadwinners, women take major responsibility for children and home (even when they are employed).

If the employment policies of the mining company reflect their commitment to gender-neutral procedures, those of the local contractors for services displayed prevailing ideas about female roles in PNG. The only company that employed a large number of women was the catering firm contracted to do the cleaning and meal provision. Women cleaned, washed clothes, served food and worked at the reception desks for the camps with low wages.

Early in the construction phase of the mine one of the local contracting companies decided to give women the opportunity to train as drivers of the large trucks and machines used in excavating the mine area and building the roads. They hired a female trainer and encouraged all Lihirian women to apply. Eight women completed training, most of them from Bougainville, and five gained employment. After a year only two Bougainvillean women remained-all the others decided that they would stay at home and avoid the hostility of male employees, husbands and villagers. The resilience of the Bougainvillean women testifies to their long familiarity with mining and their experience of exclusion from the opportunities to work in male-dominated areas. They recognised that wage disparities based on gendered occupations excluded women from jobs where the salaries were commensurate with those of men.

As the conventions of the division of labour that prevail in commerce and industry in PNG have their origins in the Australian colonial system, most local people accepted that women's jobs would be predominantly in the provision of clerical or domestic services. Similarly for the mining company-women worked in clerical positions while men would be concentrated in the skilled and semi-skilled jobs in the pit and plant site. The training reports for the early years of the mining project on Lihir reflect the acceptance of this gendered division by both men and women. Female trainees for clerical work attended courses conducted by women where they learned basic keyboard skills, filing and other office work. They were also given lessons in dress and groominglearning how to paint their nails and apply make-up. While most did not practice these newfound feminine arts, they expressed delight and enthusiasm at having acquired them. The reason that they did not wear make-up or paint their nails was that people in the village would see these as indicators of their 
sexual availability. This touches one of the major problems facing women who enter the workforce, namely, that women who move beyond the bounds of home, family or garden are often considered to be actively seeking sexual adventure. This discouraged married women from working in places where men also worked.

In countries such as PNG, where the normal division of labour tends to involve gendered tasks or familial cooperation, adjustment to working conditions that require unrelated men and women to work together can be problematic. Working women described how husbands were suspicious and jealous to the point where they were even violent towards women they suspected were 'too friendly' with their male colleagues. In one discussion about the difficulties women faced, one woman explained that shortly after she was married her husband observed her plucking her eyebrows. He instructed her that this suggested that she wanted to attract other men and was not to continue this practice.

I have been conducting research into the experiences of women in the workplace in PNG for a period of eight years with about 100 surveys completed and 30 indepth interviews. In particular I have surveyed the work experiences, hopes and aspirations of women who have been educated beyond secondary school. While most of the participants have been working in government jobs - as nurses, teachers and police officers - a significant group comprises women who work in the minerals industry. This group has the highest number of graduates and these women are younger than their public sector counterparts. We might therefore consider them to constitute the next generation of women who are potential leaders. They are characterised by a greater awareness of their capacities as professionals and unlike others they tended to express ambitions that extended beyond being successful in their current jobs. They are slightly more likely on average to control their own incomes and to live independently of other family members.

Yet the difficulties they experience at work are remarkably similar. The two problems reported by almost all women were the difficulties in gaining promotion when men would be working under their authority and the domestic problems with male partners who were jealous and suspicious of their fidelity when they had any men working with them. Seventy per cent of the women mentioned domestic violence as a problem faced by working women. As 20 per cent were single, divorced or widowed, this is an alarming proportion of women who are intimidated by men simply because they work in paid employment. It needs to be kept in mind when we consider the question of the 'empowerment of women'. It also means that simple measures such as having policies of equal pay for equal work or gender-neutral advertising of positions are not strategies that immediately facilitate or encourage equality. They operate within a social framework where there are often rigid gender roles, where 
women are unaccustomed to working with men, where men expect women to be subservient and women who 'break' gender norms are stigmatised as (at best) sexually available and (at worst) sexually promiscuous.

These problems are not insurmountable, but would require groundbreaking policies aimed at changing the preconceptions of both employers and potential employees. In speaking with women who were employed in lower paid clerical positions about the possibilities of training for positions that they considered 'masculine', many demurred on the grounds that they preferred to work with other women; they were sure that men would object and because they liked the 'clean' environment of an office.

Ideally, gender-mainstreaming policies would require a thorough analysis of the ways that the workforce operates to limit female participation, in combination with a critique of deeply entrenched gender ideologies held by employers, employees and the local community. In order to produce any effective change, there has to be political will and support from all involved. In PNG there is no indication that men in government or at the grass-roots level are prepared to relinquish their power over women's labour and fertility simply to comply with the requirements of a UN convention or the ideals of liberals in much wealthier, industrialised countries.

Similarly, mining companies have been slow to change policies and practices that diminish their profits in western countries - higher environmental standards; improved working conditions and equal opportunity in employment have been fought for in liberal democracies and adherence to higher standards generally has been achieved through legislation. In PNG, where several companies continue with practices that would not be acceptable elsewhere (such as dumping tailings and waste rock directly into rivers), there is no pressure from the government to enforce international 'best practice'.

Mining projects tend to be located in areas where people are subsistence farmers. The aspirations of modernity that people hold during the initial stages of a project rarely include female training and employment as a form of social advancement. Rather, both men and women desire improvements in infrastructure and services - especially health and education - and houses that they associate with urban locations. In both Lihir and Misima, places where I undertook social impact studies before mining began, most adult women wanted a 'western-style' house and expected that the men in their family would be employed, while they would continue to produce garden crops and perhaps have access to cash by selling some of its produce. A few hoped that their educated daughters might find employment, but none suggested that this should be a route to gender equality. These modest hopes have been only partially fulfilled in all areas where mining projects have been established. 
A gender analysis of the situation in mine-affected areas would reveal consistent, structural female disadvantage. The forces that sustain this situation are not all exogenous; in fact the most difficult to overcome are probably those deriving from the local customs, and economic and political conditions, that preceded mining. When these combine with the masculine ideologies of mining, whose main interest is profitability, the notion that 'gender mainstreaming' will be acceptable to all parties is simply fanciful.

For example, in PNG there is the problem of the 'double shift' for local women who work. In most countries, even those where women have been in the labour force for generations, the burden of domestic labour continues to be disproportionate. Mining projects occur in rural areas where there is rarely any precedent for employment for local women. In PNG, where gardening and the provision of the family's staple food is part of their domestic duties, many women who work continue to grow gardens for their food supply. In interviews, the overwhelming majority of female employees in Lihir reported that at least one of their days off each week was spent working in their gardens.

Women are expected to continue all the work of being a housewife and mother. None of the mining companies in PNG offers paid maternity leave. In Lihir basic provision was made for women to continue breastfeeding after returning to work. There was a building provided in the mining camp where babies could be cared for by a member of the family (usually a young female relative paid by the mother). It was bare except for a couple of beds and a few chairs. It had running water and sinks. It was surrounded by a wire fence and had no facilities for children to play, It would have failed Australian standards of childcare provision in terms of hygiene, space and amenities. Given the sociable and varied life available to a village infant, this could scarcely be seen as a major contribution to the welfare of mothers or children. There is no workplace childcare at any mine.

Mining companies are male dominated. The boards, management and workforce are overwhelmingly male. The prevalence of fly-in/fly-out arrangements, while minimising some of the adverse social impacts on local populations, assumes that the employee is single or is a man who has a wife who takes care of the home and family. Camp life and facilities cater to men with few concessions to women's ideas of recreation. The bar and snooker tables occupied the whole of the indoor recreation room space in both the camps where I worked.

But in considering the problems faced by women who work in mining I want to stress those home-grown gender ideologies that are reinforced within this masculine workplace rather than being challenged by notions of gender equity and non-discriminatory policies. The reasons are simple and common to many other areas of life. They have been extensively canvassed in documents 
relating to human rights and development policy and are enunciated clearly in documents such as 'Taking Action: Achieving Gender Equality and Empowering Women', by the Millennium Development Project's taskforce on gender equality (UNDP 2005). The issues identified by a gender analysis are all ones that primarily or exclusively affect women adversely.

In a chapter examining the success and failure of gender-mainstreaming in the context of achieving the Millennium Development Goals, Rekha Mehra and Geeta Rao Gupta assessed numerous NGO and government projects where this approach had been implemented. They noted that one of the factors that limited the success of the strategy was the idea that 'all staff should be responsible for its success' which in practice means that '... when mainstreaming is everyone's task, it can become nobody's responsibility' (Mehra and Rao Gupta 2006: 5). They cite the case of the Dutch government where 'an immediate consequence of the policy's adoption was closure of all gender equality offices at the local level - nobody assumed specific responsibility, procedures did not change and, as a result, gender equality goals can be swept away by the mainstream, instead of changing it.' (ibid.). The obverse can hold true also-when gender is the specific responsibility of a designated person or group within an organisation, then others do not have to ensure that policies are successfully implemented and the 'gender specialists' can be dubbed ineffectual.

But the more telling message that emerges from this document, as from others dealing with gender mainstreaming, is that all the inequalities that are identified are ones where women are the disadvantaged group. This is my main objection to the change in nomenclature. Gender mainstreaming is effectively a way of pursuing goals of gender equality that almost everywhere requires the development of policies and strategies that will improve the status of women. They will also eliminate discriminatory practices that exclude women from equal participation and allow women to benefit in economic and political activities. As this is so clearly the case, why do we not dispense with the verbiage and begin from the outset to deal with these inequities as problems that require solutions that concentrate on women?

A couple of years ago I read Stephen Lewis' (2005) book about women and HIV/AIDS in Africa. I was preparing a lecture on Women and Development in Melanesia and it was about 10 years after I had been one of the four contributing authors to the World Bank Report on Women in PNG (Brouwer et al. 1988). Looking up the UN Human Development indicators I realised how little had changed for women there. Women's lifespans have barely increased; the high rates of female illiteracy, maternal deaths, malaria, tuberculosis and HIV/AIDS tell us that women's lives have not improved much at all. The incidence of domestic violence, lack of women in political leadership and low rates of women in higher education and employment show how far they are from achieving 
gender equity. In PNG, as in many other developing countries, disparities are so extreme that any attempt to redress the imbalance could only succeed if radical changes in access to education, political participation and employment were enforced through legislation.

The following is a quick gender analysis. The difficulties that women face in getting the education and training that enables them to gain employment in mining projects are multiple and reinforce each other. The reasons for this are complex: a mixture of gender ideologies that are compounded by poverty; a lack of government commitment to the education sector; a subsistence economy that depends on female labour; and a lack of sex education and services for family planning (many secondary school students leave education because they become pregnant). The problems they face when they get there are often even greater: open antagonism; sexual harassment and discrimination in terms of opportunities for promotion, remuneration and in-service training. At home, married women regularly face the jealousy of husbands if they have to work shifts with men and husbands will try to prevent them from engaging in any training that requires them to travel. In short, a gender analysis generates an overview of a situation in which women's disadvantages are constantly compounded by the interaction of factors in the workplace and at home. There is a need for specialised support programs for women and various forms of affirmative action that enable women to participate in the workforce on something resembling equal terms.

'Gender mainstreaming' is an approach that assumes that the conditions for an increase in female participation exist in the female population and can be redressed by adjustments and policy changes that allow women to do such things as enter the workforce. My research and experience of working in PNG over the last 30 years suggest that improving gender equity is a lot more complicated. Whatever gender mainstreaming might be in academic terms, by the time it gets into aid projects or workplace policies it has become 'add women and stir' with nobody prepared to actually do this. If gender equality is to be achieved in a period of a decade, specialised programs for women are needed.

Stephen Lewis' work on HIV/AIDS in Africa provides a discussion of this, which for all its polemic struck me as directly applicable to women's employment in mining in PNG:

... gender mainstreaming is a pox for women. The worst thing you can do for women is fold them into the mandates of ... [broader development programs]. Once you've mainstreamed gender it's everybody's business and nobody's business. Everyone's accountable and no one's accountable. I don't know who thought up this gender mainstreaming guff, but I often wonder what their motives were.... Gender mainstreaming might work 
if we had what sports and financial enthusiasts call 'a level playing field', that is to say, if there were real equity and equality between women and men. Then gender mainstreaming becomes a way of maintaining that equality. But when you start from such gross inequality, mainstreaming simply entrenches the disparities (Lewis 2005: 125-26).

My experience in PNG has convinced me that if women are ever to operate on a 'level playing field' then specific attention will need to be given to overcoming the structural disadvantages and inequities that exclude and disenfranchise women before any project (including mining projects) is embarked upon. Mining companies are private enterprises and although they might be agents of change, they should not be usurping the role of the government. While they might, for instance, develop training programs aimed at increasing female participation in employment, it is not appropriate that they should be the implementing agents of UN conventions such as that for the Elimination of Discrimination against Women (CEDAW). Programs and projects that are aimed at improving women's education and training, policies ensuring that women have access to services that deal with their reproductive health, legislation that requires the provision of work-based childcare or equal pay - these are matters for governments to establish and enforce. In the current environment, where women's disadvantages are so entrenched, there is an urgent need for policies that are directed exclusively to improving women's lives and opportunities so that they are able to participate in social and economic life on equal terms with men.

Government actions in the form of legislation and enforcement of antidiscriminatory policies can 'level the playing field'. Commercial enterprises can only work in the context of national policies and laws. In the mining industry in PNG the steps that can be taken to improve opportunities and conditions for women will still have to take the form of affirmative action if equality and equity are to be gained within the next decade. At present there are a few aid projects that are working exclusively with women in order to change their status, increase participation in political affairs and engage in campaigns for recognition of their rights, but there is little will within the government to effect such changes. Mainstreaming within an industry will simply mean that gender-specific disadvantage is ignored and that companies continue to make the excuses that 'women did not apply', or they 'cannot work shifts because of domestic responsibilities' or 'there were no suitable female applicants'. In my experience, mainstreaming means that women's specific interests are subjugated to the needs and objectives of a project. In aid projects, the mainstreaming agenda is linked to cost-cutting; restructuring departments so that women's issues are diminished in importance and funding is based on large programs that subsume women as just another factor in the overall project. In the mining industry in 
Gendering the Field

PNG, where there has never been a tradition of even noticing women's interests as an issue until they are manifest as social problems, it means they would be marginalised from the outset and 'disparities would be entrenched'.

\section{References}

Bonnell, S., 1999. 'Social Change in the Porgera Valley.' In C. Filer (ed.), Dilemmas of Development: The Social and Economic Impact of the Porgera Gold Mine, 1989-1994. Canberra: Asia Pacific Press (Pacific Policy Paper 34).

Brouwer, E. B.M. Harris, and S. Tanaka (eds), 1998. Gender, Economic Development and the Status of Women in Papua New Guinea. Washington DC: World Bank, East Asia and Pacific Region.

ECOSOC (Economic and Social Council of the United Nations), 1997. 'Mainstreaming the Gender Perspective into all Policies and Programs in the United Nations System.' Geneva: United Nations.

Golub, A., 2006. 'Who is the "Original Affluent Society"? Ipili "Predatory Expansion" and the Porgera Gold Mine, Papua New Guinea.' The Contemporary Pacific 18(2): 265-92.

Hammar, L., 2008. 'Mobility, Violence and the Gendering of HIV in Papua New Guinea.' The Australian Journal of Anthropology 19(2): 125-250.

Lewis, S., 2005. Race against Time: Searching for Hope in AIDS-Ravaged Africa. Melbourne: Text Publishing.

Macintyre, M., 2005. 'Social Impact Report for Lihir, 2004'. Melbourne: University of Melbourne.

Mehra, R. and G. Rao Gupta, 2006. Gender Mainstreaming: Making it Happen. Washington: International Centre for Research on Women.

Pattenden, C., 1998. 'Women in Mining: A Report to the Women in Mining Taskforce.' Carlton: Australasian Institute of Mining and Metallurgy.

UNDP (United Nations Development Programme), 2005. Taking Action: Achieving Gender Equality and Empowering Women. London: Earthscan.

Yrke, M., 2005. "What You Do is Who You Are": Gender Identity in the Resources Industry. Perth: University of Western Australia (Ph.D. thesis). 